\title{
O trabalho do historiador em foco: reflexões sobre a Historik de Johann Gustav Droysen (1808-1884)
}

\author{
The work of the historian in focus: reflections on the Historik of \\ Johann Gustav Droysen (1808-1884)
}

Julierme Morais ${ }^{1}$

\begin{abstract}
Resumo: No artigo em voga procuraremos mapear a contribuição da Teoria da História do historiador alemão Johann Gustav Droysen (1808-1884) no processo de cientifização da História no século XIX, bem como refletir sobre a sua atual importância nos estudos históricos. Para tanto, preliminarmente incorremos em uma análise do que ele concebe como História, Método Histórico e Tarefa da Teoria da História. Em seguida, buscamos demonstrar a maneira pela qual ele propõe que se constitua a operação historiográfica, composta pela Metódica, Sistemática e Tópica. Por fim, procuramos tecer considerações finais sobre a efetiva contribuição de Droysen para o debate sobre o ofício do historiador na atual conjuntura da modernidade reflexiva.
\end{abstract}

Palavras-chave: Teoria da História. Johann Gustav Droysen. Modernidade Reflexiva.

\begin{abstract}
In the article in vogue, we will try to map the contribution of the Theory of History of the German historian Johann Gustav Droysen (1808-1884) in the process of scientific history in the Nineteenth Century, as well as reflect on its current importance in historical studies. In order to do so, we preliminarily undertake an analysis of what he conceives as History, Historical Method and Theory of History task. Next, we try to demonstrate the way in which he proposes to constitute the historiographic operation, composed by the Methodical, Systematic and Topical. Finally, we seek to make final remarks about Droysen's actual contribution to the debate on the office of the historian in the current conjuncture of Reflective Modernity.
\end{abstract}

Keywords: Theory of History. Johann Gustav Droysen. Modernidade Reflexiva.

\section{Introdução}

O filólogo, tradutor e historiador Johann Gustav Droysen (1808-1884), malgrado certo esquecimento oriundo de interpretações equivocadas relativas aos princípios, abordagens e características do historicismo alemão (CALDAS, 2006), possuiu um papel fundamental na constituição dos estudos históricos modernos ${ }^{2}$. Inserindo-se na chamada Escola Histórica

\footnotetext{
1 . Doutor em História pela Universidade Federal de Uberlândia (UFU). Docente na Universidade Estadual de Goiás (UEG), Morrinhos, GO, Brasil. ORCID: http://orcid.org/0000-0001-5257-6691. E-mail: juliermemorais27@gmail.com

2 A teoria da História de Droysen, ao longo do século XX, passou por certo abandono até Jörn Rüsen produzir sua tese de doutorado acerca do teórico e historiador. Cf. RÜSEN, 1969. Desde então, Rüsen se empenhou na discussão sobre a didática da história como um dos papeis fundamentais do pensamento histórico, tendo Droysen como sua matriz teórica. Cf. RÜSEN, 2010abc. No Brasil, a revisita à obra de Droysen tem se dado por alguns trabalhos (teses, dissertações, artigos, capítulos de livro e livros) que, por um lado, tratam dos conceitos de Bildung, compreensão e helenismo e, por outro, de temas como hermenêutica, pensamento histórico e
} 
Alemã do século XIX, ao lado de nomes do quilate de Leopold von Ranke, Theodor Mommsen e Jacob Burckhardt, Droysen tornou-se um dos mais importantes historiadores de seu tempo. Isso porque a sua contribuição na fundamentação teórica e metodológica dos estudos históricos é notável, pois, além de interlocuções muito pertinentes com Georg W. F. Hegel, Immanuel Kant, Alexander von Humboldt, Johann Gottfried von Herder e Johann Wolfgang von Goethe, a sua fortuna crítica inaugurou novas perspectivas para a definição do método histórico e para a autonomização da História no campo das ciências humanas (BENTIVOGLIO, 2009).

Johann Gustav Droysen nasceu na Polônia em 1808, mudando-se para Berlim em 1820, onde estudou filosofia e filologia clássica na Universidade de Berlim tendo oportunidade de ser aluno de Georg W. F. Hegel e August Börckh. Após concluir seus estudos em Berlim, ter traduzido e comentado dramas gregos de Ésquilo e Aristófanes, escrito uma biografia de Alexandre da Macedônia - obra em três volumes intitulada História do helenismo -, bem como trabalhado no ensino secundário, em 1840 Droysen transferiu-se para Kiel, lugar a partir do qual se tornou professor efetivo da Universidade de Kiel. Por lá passou a estudar a História política de seu presente e a atuar politicamente, produzindo textos como Conferências sobre as guerras da liberdade e, a exemplo de inúmeros historiadores do século XIX ${ }^{3}$, se interessando por política na prática institucionalizada, ao exercer o cargo de deputado na Assembleia Nacional Alemã, em Frankfurt, entre 1848 e 1849.

A partir de 1851, o historiador lecionou na Universidade de Iena e, dando prosseguimento no interesse por História política, iniciou a redação dos quatorze volumes inacabados de História da política prussiana, além de publicar os três volumes da biografia do comandante militar prussiano Conde Yorck von Wartenburg. Foi também em Iena que Droysen se abriu para os estudos de Teoria e Metodologia da História, ministrando cursos de Enciclopédia e Metodologia da História, entre 1857 e 1858. Em 1859, ano em que retornou como professor para a Universidade de Berlim os cursos de Enciclopédia e Metodologia da História se repetiram até aproximadamente a sua morte, em 1884. Eles deram origem, ainda em 1858, ao Manual de Teoria da História (Grundriss der Historik) ${ }^{4}$, texto difundido entre seus alunos e pares intelectuais que seria republicado com maior difusão no decorrer dos séculos XIX e XX (ASSIS, 2010, 2014a; BENTIVOGLIO, 2009).

O Manual de Teoria da História (2009) é a sua obra que mais nos interessa na reflexão aqui pretendida, pois no presente ensaio, que gira em torno de reflexões acerca de Teoria e Metodologia da História - área dos estudos históricos muitas vezes ignorada nos níveis intro-

didática da História, problematizando-os, especialmente no sentido de compreender o modo pelo qual o teórico e historiador alemão enxergava a produção do conhecimento histórico e seus desdobramentos na vida prática dos indivíduos. Cf. ASSIS, 2010, p. 31-36; 2014a, p. 1-18; 2014b; BARROS, 2011, p. 97-128; CALDAS, 2004; 2006, p. 95-111; 2007, p. 1-18; 2008, p. 107-124; 2013, p. 36-55; GUERRA, 2013, p. 59-70; SAMMER, 2012.

3 Fortemente influenciados pelo ideário político, em especial aquele das aspirações de unificação e resgate de um passado específico, particular e identitário alemão sob égide do Estado Prussiano, diversos historiadores da Escola Histórica Alemã, além de obras históricas, produziram textos políticos ou exerceram alguma atividade política importante. Aos interessados, Júlio Bentivoglio destaca inúmeros nomes (BENTIVOGLIO, 2009, p. 42-46).

4 O Manual de Teoria da História (Grundriss der Historik) consiste em uma versão sintética de Historik, cuja edição mais completa foi organizada por Peter Leyh. Cf. DROYSEN, 1977. A versão utilizada neste ensaio é a brasileira, organizada e traduzida por Sara Baldus e Julio Bentivoglio. Cf. DROYSEN, 2009. 
dutórios da formação de professores de História e historiadores -, pretendemos problematizar a contribuição de Droysen no processo de cientifização da História no século XIX, bem como sinalizar a sua importância no atual contexto dos estudos históricos. Com tal intenção não vislumbramos esgotar o assunto, tampouco expor um ponto de vista unívoco, mas, sim, mesmo correndo o risco da generalização e/ou simplificação, tornar mais palpável ao potencial público desse ensaio a Teoria da História (Historik) de Gustav Droysen.

\section{História, Método Histórico e Tarefa da Teoria da História}

À luz do já exposto, pode-se reforçar que Gustav Droysen construiu suas reflexões sobre Teoria e Metodologia da História na Alemanha do século XIX, lugar e tempo no qual efetivamente ocorreu a inserção do conhecimento histórico no campo epistemológico das ciências humanas sob forte apelo de uma nova forma de consciência histórica. A difusão desta consciência se deu concomitante à institucionalização da pesquisa histórica sob forma de disciplina acadêmica especializada, na qual o procedimento de tornar presentes as ações humanas pretéritas foi articulado à elaboração crítica das fontes históricas (MARTINS, 2002)5.

Precisamente no interior da Escola Histórica Alemã, onde se potencializou o que se convencionou chamar de historicismo alemão, cuja característica fundamental consistiu em “[...] elaborar as categorias mestras da ciência histórica, com as quais se entende o passado humano como História, as regras metódicas, com as quais a investiga, e a pretensão pedagógica, com a qual deveriam ser concretizadas" (MARTINS, 2008, p. 42), a Teoria da História (Historik) de Droysen é um exemplo nítido de uma decisiva evolução do pensamento histórico, alicerçada na proposição de uma fundamentação metódico-documental, em torno da qual foi construído um normativismo histórico que definiu os parâmetros metódicos estipulados como obrigatoriedade para que a História se enquadrasse nos padrões vigentes de uma ciência (MARTINS, 2010).

Gustav Droysen, em seu Manual de Teoria da História (2009) (Grundriss der Historik), impõe-se ao empreendimento de aprofundar-se nas questões da História como ciência, fundamentar o seu método e a sua tarefa e, a partir do que foi reconhecido de sua natureza, desenvolver a sua fisionomia própria. Concordando com Jörn Rüsen, pode-se afirmar que Droysen parte do questionamento acerca de como se tem de estudar a História, como se deve começar e o que se deve fazer no sentido de se tornar um historiador, nos dando como resposta uma exposição sistemática do campo e do método de nossa ciência (RÜSEN, 2010a).

Com efeito, nota-se que, ainda no século XIX, Droysen se impõe a tarefa de sistematizar o que na segunda metade do século XX o historiador francês Michel de Certeau (2007) denominou de "operação historiográfica". Para tanto, tal sistematização deveria ser introduzida com algumas questões expressivas que Droysen não se furta de problematizar, pois, já nas primeiras páginas de sua obra, sinaliza o que entende por $1^{\circ}$ ) História (Geschichte); $2^{\circ}$ ) Método

5 Exemplo nítido dessa necessidade do trabalho com as fontes históricas é o surgimento da coleção nacional de fontes históricas na Alemanha: a Monumenta Germaniae Historica, em 1819. Cf. (MARTINS, 2002). 
Histórico (Historische Methode); e $3^{\circ}$ ) Tarefa da Teoria da História (Aufgabe der Historik). Em sua caracterização do que é História (Geschichte), afirma:

O movimento incessante no mundo dos fenômenos nos permite conceber as coisas como estando em constante devir, seja esse devir como algo que se repete periodicamente, seja como algo que parece repetir-se e crescer por intensificação e acumulação contínuas. Naqueles fenômenos, nos quais se manifesta a nós um tal avanço, que se encontram em uma sucessão, o fator do tempo é considerado por nós como sendo decisivo. É isso que entendemos e resumimos como História. Só o que é humano aparece aos olhos dos homens como estando em progressão crescente e em intensificação constante, e este movimento de progressão e de intensificação constituem a sua essência e tarefa. A soma desse crescente infatigável é o mundo ético. E é somente nesse último que o termo História encontra sua aplicação integral (DROYSEN, 2009, p. 35-36).

O historiador parte da ideia de que a História pode ser conceituada como entendimento $a$ posteriori elaborado acerca das ações humanas (feitos) pretéritas. Em outros termos, as ações humanas (feitos) devem ser compreendidas como História somente quando se tornam presentes por meio de rememoração consciente: interpretadas enquanto passado (RÜSEN, 2010a). Esse procedimento de racionalização é efetuado no mundo ético: lugar e tempo presente no qual as ações humanas (feitos) são rememoradas como pretéritas. Neste prisma reflexivo é interessante notar a similaridade da proposta de Droysen às perspectivas segundo as quais a história somente seria dotada de sentido no presente (BLOCH, 2001), bem como de que toda História é História contemporânea (CROCE, 1964). Nesse sentido, o teórico prossegue em seus argumentos, enfatizando que

A ciência da História é o resultado de percepções empíricas, de experiências e da pesquisa. [...] Todo empirismo se baseia na 'energia específica' dos nervos sensoriais, em que, por meio de excitação, o espírito recebe não 'cópias', mas signos dos objetos do mundo exterior, que produziram essa estimulação. Assim, o espírito humano desenvolve sistemas de signos que, por efeito de correspondência externa, apresentam os objetos, constituindo o mundo das ideias. [...] Toda pesquisa empírica se rege sob coordenadas por nós orientadas. Ela não pode se orientar além destas coordenadas que, por sua presença imediata, se prestam a uma percepção sensível (DROYSEN, 2009, p. 36-37).

Subjaz às suas asserções uma postura contrária à objetividade absoluta do conhecimento histórico e, assim, a negação da noção rankeana de objetividade do historiador nos procedimentos de pesquisa. Com tal argumento, o historiador nos dá mostras de sua capacidade em pensar teoricamente. Para ele, a História (Geschichte) não é somente uma ciência, mas uma ciência empírica. O termo empiria não é tomado tal como era proposto pelos filósofos iluministas e/ou idealistas, mas, sim, distancia-se justamente por enfatizar o caráter especulativo daquilo considerado empírico, ou seja, avesso à formulação de leis gerais, fruto de representações por meio da percepção de signos dos objetos do mundo exterior pelo pensamento 
humano. Em suma, como propõe Pedro Caldas: “[...] Droysen já sabia, em meados do século XIX, ser impossível uma objetividade garantida metodologicamente, e, tal como Nietzsche faria décadas depois, chamará de "eunuco" o historiador que cultivar esta ilusão de objetividade" (CALDAS, 2007, p. 54).

Em face dessa perspectiva, Gustav Droysen enseja demonstrar que a cientificidade do conhecimento histórico reside nos pressupostos metodológicos que controlam os meios de sua produção. É nesse ponto reflexivo que ele abre lastro a considerações atinentes ao entendimento do que é Método Histórico (Historische Methode), ressaltando que “[...] o método da pesquisa histórica é determinado pelo caráter morfológico de seus materiais. A essência do método histórico é de compreender ao pesquisar" (DROYSEN, 2009, p. 38). Por esse motivo, afirma:

De acordo com os objetos estudados e a natureza do pensamento humano, existem três métodos científicos: o método especulativo (filosófico ou teológico), o físico e o histórico. A sua essência é: reconhecer, esclarecer e compreender. [...] O mundo ético, movido por muitos fins e objetivos, decisivamente - assim pressentimos e cremos - ele tem por fim último o desenvolvimento perpétuo, em intensificação permanente [...] Observado segundo a sucessão de suas transformações, esse mundo é para nós a História. A cada passo dado adiante nesse tornar-se e crescer, amplia-se e aprofunda-se a compreensão da História, isto é, o seu ser compreendido e o seu compreender; o conhecimento sobre ela é ela mesma; a História precisa aprofundar, sem descanso, as suas pesquisas, ampliar seus horizontes. Os acontecimentos históricos têm a sua verdade nos poderes éticos (tal como as coisas da natureza os têm nas suas 'leis' mecânicas, físicas, químicas, etc.): estes são a sua respectiva concretização. Pensar historicamente significa ver, nessas realidades, a sua verdade (DROYSEN, 2009, p. 41-42).

Tal esboço teórico se dá no intuito de evidenciar como método propriamente histórico a compreensão $0^{6}$, que figura entre o método especulativo (filosófico ou teológico) e o físico-matemático (ciências naturais). Para explicar esse lugar do Método Histórico (Historische Methode), Droysen sinaliza que os objetos do historiador são expressões humanas. Sendo assim, ao passo que somente o mundo humano é compreendido pela ideia de progresso e continuidade: como histórico -

em um mundo ético que é regido por poderes éticos -, a compreensão é o único método viável para entender as alterações e experiências humanas ao longo do tempo e de acordo com as carências de orientação do presente vivido pelos sujeitos do conhecimento histórico. Portanto, a ciência da História em Droysen procura articular especulação e empiria, espírito e natureza (CALDAS, 2010).

Na Alemanha, desde o último terço do século XVIII, os termos Historie (significado de conhecimento, narrativa e ciência da História) e Geschichte (significado de conjunto de acontecimentos) são fundidos no único conceito: Geschichte (KOSELLECK, 2013, p. 119). A par desse

6 Em Historik, versão mais completa de Grundriss der Historik, Droysen aprofundará a questão e desenvolverá o conceito de compreensão investigativa (Forschendes Verstehen), como sendo a essência de todo procedimento metodológico na obtenção do conhecimento histórico. Cf. DROYSEN, 1977. 
processo e preocupado em definir uma especificidade para o conhecimento histórico, Gustav Droysen entende que a ciência da História (um dos significados abrangidos por Geschichte) carece de uma definição mais precisa. Por esse motivo, o historiador se apropria do termo Historik utilizado por Georg Gottfried Gervinus (2010) para significar Teoria da História e o diferencia de Geschichte no fito de estabelecer suas tarefas, salientando:

A teoria da História não é uma enciclopédia das ciências históricas, nem uma filosofia (ou teologia) da História, tampouco uma física do mundo histórico, muito menos uma poética para a historiografia. Ela deve postular como sua tarefa ser um organon do pensamento e da pesquisa histórica. [...] A teoria da História abrange a Metódica da pesquisa histórica, a Sistemática do que é historicamente pesquisável e a Tópica dos modos de exposição do historicamente pesquisado (DROYSEN, 2009, p. 42-43).

Os argumentos são precisos: à Teoria da História (Historik) cabe o papel de constituir-se em um instrumento amplo a ser utilizado pelos historiadores no sentido de produzir conhecimento histórico compreensivo. Tal instrumento abrange uma Metódica (Methodik) da pesquisa histórica, uma Sistemática (Systematik) do que é historicamente pesquisável e uma Tópica (Topik) dos modos de exposição daquilo pesquisado.

\section{Metódica, Sistemática e Tópica}

Para Droysen, a Metódica (Methodik) constitui-se na metodologia empregada pelo historiador em seu processo de pesquisa. Dividindo-se em três momentos - Heurística (Heuristik), Crítica (Kritik) e Interpretação (Interpretation) -, o método histórico compreensivo é desdobramento da ideia segundo a qual o conhecimento histórico sempre será insuficiente e parcial, uma vez que esbarra no limite da compreensão da relação passado-presente mediada por um sujeito histórico também limitado. É justamente o papel do sujeito do conhecimento histórico no processo de produção historiográfica que se torna objeto de reflexão de Droysen nos três estágios da metodologia.

Problematizando a Heurística (Heuristik) da pesquisa histórica, ele afirma que "O ponto de partida de toda pesquisa é a questão histórica. A heurística nos fornece os materiais para o trabalho histórico, ela é com a arte do mineiro, de encontrar e trazer à luz, um trabalho subterrâneo" (DROYSEN, 2009, p. 46). Ou seja, o procedimento heurístico consiste no momento inicial de toda pesquisa histórica, cuja mola propulsora é uma questão elaborada segundo o reconhecimento por parte do historiador dos traços do passado em seu presente, organizando assim o seu material histórico. É do processo heurístico, especialmente da questão histórica que, para Droysen, resultarão quais são os vestígios, os monumentos e as fontes a serem mobilizadas pelo historiador na busca da resposta à questão histórica. A partir desse procedimento a apreensão por parte do historiador será sempre em consonância com o seu ponto de vista alocado no mundo contemporâneo, cuja finalidade também varia, podendo 
consistir em mero divertimento, ou até mesmo comercial (DROYSEN, 2009). Como ressalta Luiz Sérgio Duarte da Silva, para Droysen,

O passado só nos chega através de pistas (dele só podemos construir imagens, representações: o passado é um excelente exemplo de presença-ausência), mas essas pistas só podem ser lidas a partir de uma postura investigativa. Nesse sentido, o historiador é juiz: ele coage, obriga, interroga. A especificidade do conhecimento histórico está dada pelo caráter compreensivo. A identidade de sujeito e objeto lhe obriga essa postura (SILVA, 2002, p. 154).

Subjaz aos argumentos a ideia segundo a qual Droysen, ao enfatizar que as perguntas partem do historiador para os objetos da pesquisa histórica, toca na questão da liberdade do sujeito pesquisador e na impossibilidade de ser imparcial, premissa tão em voga no século XIX e tão mal interpretada ao longo do século XX. Nesta medida, a dimensão filosófica e ética em tal proposição distancia o teórico da postura, por exemplo, de Leopold von Ranke, para quem a metodologia da História resume-se à crítica documental, tomada enquanto estágio técnico da produção do conhecimento histórico (BARROS, 2011).

Elaborando sua visão do que consiste a Crítica (Kritik), Droysen parte da negação de certa noção de fato histórico bastante difundida no século XIX, com o seguinte argumento:

A crítica não busca o "fato histórico propriamente dito", pois cada chamado fato histórico, desconsiderando os meios, o contexto, as condições e as finalidades que atuaram conjuntamente, são um complexo de atos de vontade, muitas vezes, de muitos atos de vontade que auxiliam, ou que inibem e que, como tais, já são passado juntamente com o presente ao qual pertenceram e ainda existem somente nos vestígios do que foi feito naquela época ou formado graças a eles, ou estão disponíveis sob a forma de opiniões e lembranças (DROYSEN, 2009, p. 49).

A crítica não se resume na procura do fato histórico, na medida em que todos os fatos correspondem a atos de vontade pertencentes a circunstâncias pretéritas - e já tidas como tal que chegam ao pesquisador na forma de vestígios, fontes e monumentos. Os atos de vontade, nesse sentido, retiram o caráter de objetividade dos fatos históricos porque os últimos somente são recuperados através de elementos do passado que são inquiridos pelo historiador. Especificamente com esta postura, que considera os fatos históricos enquanto atos de vontade que chegam ao presente somente como vestígios, fontes e monumentos, Droysen trata de delimitar a tarefa da crítica histórica, ressaltando:

A tarefa da crítica é determinar em qual relação se entrelaça o material ainda disponível em relação aos atos de vontade, dos quais ele oferece testemunho. As formas da crítica são determinadas pela relação entre o material a ser explorado e os atos de vontade, dos quais receberam sua configuração (DROYSEN, 2009, p. 50).

Colocada nestes termos, a crítica é o estágio da produção do conhecimento histórico no qual o pesquisador investiga em que medida o material histórico - vestígios, fontes e documentos - 
está relacionado ou não com as circunstâncias e ações dos indivíduos do passado que ele pretende lançar luz. Para que isso ocorra, a crítica ao material histórico deve procurar sua autenticidade, sua época e seu posterior, sua exatidão e, por fim, proceder uma classificação crítica do material analisado (DROYSEN, 2009). Neste último estágio da crítica, Droysen enfatiza:

A classificação crítica não tem somente a incumbência de guiar sob o ponto de vista da sequência temporal cronológica. Dependendo de como ela consegue agrupar os mesmos materiais de acordo com mais variados pontos de vista, tanto mais pontos fixos resultarão das linhas cruzadas sucessivas [...] (DROYSEN, 2009, p. 53).

Com esses argumentos, o teórico dá mostras de que as críticas desferidas, no limiar do século XIX, pelo sociólogo durkheiminiano François Simiand (2003), especialmente ao "ídolo cronológico" da "tribo dos historiadores", não se adequam à proposta de sua Teoria da História (Historik). A cronologia do material à luz das asserções de Droysen não é cultuada, pelo contrário: pode muito bem ser abandonada se tal procedimento abrir caminho para o historiador agrupar o material histórico da maneira mais pertinente as suas intenções exploratórias. Por esse motivo, Droysen fecha suas considerações sobre a crítica, apontando que o resultado de tal procedimento não é o “fato histórico propriamente dito", mas, sim, a segurança de que o material histórico preparado permitirá ao historiador uma interpretação relativamente correta (DROYSEN, 2009).

No seu intento de esmiuçar os estágios da Metódica (Methodik), Gustav Droysen passa então a problematizar o procedimento interpretativo. Para tanto, inicia suas considerações demarcando espaço de atuação e posição em relação a seus contemporâneos, ao afirmar:

Nem a crítica procura as origens, nem a interpretação as exige. No mundo ético nada existe que não tenha sido mediado. A pesquisa histórica não tem por ambição explicar, ou seja, não pretende deduzir do anterior o posterior; os fenômenos necessariamente como efeitos de evoluções e leis que os regem. Se a necessidade lógica do posterior residisse no anterior, então existiria, ao invés do mundo ético, um análogo de matéria eterna e da transformação dos materiais. Se a vida histórica fosse somente uma nova geração do que é sempre igual, então ela seria sem liberdade e sem responsabilidade, desprovida de conteúdo ético; ela seria apenas natureza orgânica. A essência da interpretação é ver realidades nos acontecimentos passados, com toda a abundância das condições que exigiram sua concretização e existência (DROYSEN, 2009, p. 53-54).

Aqui, Droysen mais uma vez nos demonstra que as críticas posteriores de François Simiand (2003) ao "ídolo cronológico" da "tribo dos historiadores", ao menos a ele, não faziam sentido. Retém-se de sua colocação que, tanto na crítica quanto na interpretação, a procura pelas origens consiste em uma espécie de pecado original. O mundo ético (humano e moral) não permite ser explicado por meio da causalidade, segundo o modelo positivo: post hoc ergo propter hoc, mas, sim, ser interpretado e compreendido pela mediação temporal e circunstancial, típicas das relações 
humanas com e no tempo (mundo ético). Portanto, para Droysen, "A essência da interpretação é ver realidades nos acontecimentos passados, como toda a abundância das condições que exigiram sua concretização e existência” (DROYSEN, 2009, p. 54). Posta neste sentido, a interpretação corresponde ao momento em que o historiador poderá oferecer respostas às questões colocadas no processo heurístico, interligando os procedimentos e sempre tendo em vista o mundo ético. Tais repostas podem ser procuradas à luz dos modelos da interpretação pragmática, da interpretação das condições, da interpretação psicológica e da interpretação das ideias. Estas, podendo coexistir sem hierarquias, apesar do traço mais subjetivo do último modelo de interpretação.

Discorrendo acerca da interpretação pragmática, Droysen pontua que a mesma “[...] abrange os vestígios e as descrições de ocorrências reais em tempos remotos, verificados e classificados pela crítica, de acordo com o nexo causal que reside na natureza desse andamento dos eventos [...]" (DROYSEN, 2009, p .54). Nesse processo, havendo riqueza de material basta o método demonstrativo, ao passo em que, caso haja insuficiência, cabe o método comparativo, que pode ser mediado por uma hipótese elaborada pelo historiador com base na contextualização. Em poucas palavras, a interpretação pragmática consiste na procura de respostas pela interrogação do material histórico por meio de nexos causais. Isso não consiste em um refluxo de sua perspectiva, pois os nexos causais são traçados pelo pesquisador à luz de certa temporalidade e circunstâncias alicerçadas no mundo ético. A interpretação das condições, em Droysen, consiste no procedimento de reunião de informações acerca do espaço, do tempo e dos meios materiais que possibilitaram a geração do material histórico questionado pelo pesquisador. Esse procedimento, em sua concepção, somente é possível se existirem nos vestígios e na interpretação as condições que estavam contidas de forma ideal na ocorrência dos eventos reais em tempos remotos. No tocante à interpretação psicológica, o teórico ressalta que o papel dos historiadores é procurar no fato os atos de vontade que o produziram. Dessa maneira, tal interpretação é capaz de reconhecer o sujeito que desejou tal fato, a energia de sua vontade, bem como a maneira pela qual ela influenciou o curso dos acontecimentos e/ou seus interesses (DROYSEN, 2009). O historiador, todavia, reconhece os limites da tal interpretação e faz uma ressalva:

[...] o ser humano reconhece o ser humano, mas apenas superficialmente ele percebe seus atos, sua fala, sua expressão facial, porém sempre somente nesse momento; comprovar que ele compreendeu totalmente e corretamente, isso ele não é capaz. [...] As coisas seguem seu rumo, apesar da vontade boa ou má daqueles por meio dos quais se realizam (DROYSEN, 2009, p. 56-57).

A História não é construída ao longo do tempo somente de aspirações individuais, tampouco é possível que o historiador (ser humano) comprove que compreendeu totalmente e corretamente os sujeitos históricos (outros seres humanos) à luz de sua individualidade. Posto isso, é no limite da interpretação psicológica que Droysen aloca a interpretação das ideias. Para problematizar este modo de interpretação, ele segue a prerrogativa segundo a qual o ser individual constrói seu mundo (ético) compartilhando poderes éticos - sistema de ideias que perduram por uma 
temporalidade maior do que a do ciclo de vida humano -, na medida em que cada época constitui-se em um complexo de concretização de todos seus poderes éticos, independentemente da intensidade ou da carência de sua fragmentação (DROYSEN, 2009). Assim sendo, o mundo ético no qual residem os poderes éticos, em consonância com as questões a serem respondidas pertinentes ao material histórico, formulam o lugar seguro no qual a interpretação das ideias procura reconhecer as aspirações presentes no período no qual o material histórico foi constituído, seja por meio de uma perspectiva estática - cuja análise do estado das circunstâncias éticas desconsidera seu desenvolvimento progressivo - , seja através de uma abordagem dinâmica - em que são levados em consideração os momentos progressivos daquele estado de coisas (DROYSEN, 2009). Destarte, "O pensamento ou a complexidade dos pensamentos que a interpretação salienta, em qualquer curso de eventos, é para nós a verdade daquele curso de acontecimentos" (DROYSEN, 2009, p. 59). Nestes termos, como sugere Pedro Caldas,

O mundo dos objetos históricos, se construído pela interpretação do historiador, tampouco será uma mera reprodução de sua mente, mera folha em branco na qual o historiador haverá de inscrever o que melhor lhe aprouver. A História é ambígua, e, por esta razão, é a própria tematização da relação entre o homem e a sua circunstância (CALDAS, 2007, p. 54).

Em poucas palavras, o conhecimento histórico é produzido por sujeitos inseridos em um lugar social, que também é histórico, composto de circunstâncias e capacidade de influenciar o trabalho do próprio historiador. Por esse motivo, Droysen passa então a problematizar a Sistemática (Systematik) e imediatamente ressalta com muita clareza na exposição:

O campo do método histórico é o universo do mundo ético. O mundo ético é, em seu momento presente de constante mudança, uma confusão caótica interminável de negócios, estados de coisas, interesses, conflitos, paixões, etc. Pode ser observado e tratado cientificamente de acordo com vários pontos de vista técnicos, jurídicos, religiosos, políticos, etc. O que nele ocorre diariamente não é feito ou desejado por nenhum estudioso como História. Somente o modo peculiar de encarar o acontecimento vivido diferente dos feitos comuns "faz do passado História”. Apreender os sentidos do mundo ético, apreendê-los de acordo com seu desenvolvimento e sucessão, de acordo com a sequência causal de seu movimento, denomina-se apreender historicamente. O mistério de todo o movimento é sua finalidade. Quando a interpretação histórica observa, no movimento do mundo ético, o seu desenrolar, reconhece a sua direção, vê o objetivo das finalidades a se realizar e a se desnudar, ela tira conclusões sobre a finalidade última na qual o movimento se completa, na qual aquilo que move o mundo humano, impulsionando-o a seguir sempre em frente, sem parada, é paz, perfeição, presente eterno (DROYSEN, 2009, p. 61-62).

Subjaz a essas considerações o fato segundo o qual a aplicabilidade da Metódica (Methodik) se dá na Sistemática (Systematik) - cuja essência consiste em apresentar o ponto de vista sob o qual assentam a heurística, a crítica e a interpretação histórica - para que a apreensão do 
movimento do mundo ético (a História) desdobrado de poderes éticos resulte em uma presentificação do pretérito com sentido histórico. A Sistemática (Systematik) de Droysen, nesta medida, consiste em uma reflexão quádrupla. 1) sobre as aspirações, concepções e ideais que movem as ações humanas (poderes éticos); 2) acerca dos sentidos do conjunto destas ações e seus resultados (mundo ético); 3) atinente à manifestação do mundo ético que se dá nos agrupamentos humanos de diversos tipos (comunidades éticas); 4) pertinentes à maneira pela qual o historiador deve lidar com o movimento contínuo do mundo ético no procedimento de compreensão, que é efetuado no presente. Assumida essa pressuposição, em Gustav Droysen o mundo ético deve ser observado pelo trabalho histórico por meio da Metódica (Methodik) à luz da matéria na qual ele se forma, das formas nas quais ele se constitui, dos trabalhadores através dos quais ele se constrói e dos fins concretizados mediante seu movimento.

Acerca do trabalho histórico segundo suas matérias, Droysen pontua que seu material consiste no que é dado pela natureza e naquilo existente em virtude do devir histórico. Propondo uma continuidade entre mundos natural e espiritual, o teórico deixa claro que a pesquisa, a compreensão, o domínio e a configuração da natureza efetuada pelo trabalho histórico a eleva ao patamar do mundo ético (conjunto das ações humanas e seus resultados) (DROYSEN, 2009).

No que tange ao trabalho histórico segundo suas formas, Droysen deixa claro que as formas nas quais ele se move são as comunidades éticas (agrupamentos humanos), cuja tipologia se resume a três -1) as comunidades naturais (família, vizinhança, tribo e povo); 2) as comunidades ideais (fala e linguagem, belo e artes, verdade e ciências, sagrado e religiões); 3) as comunidades práticas (esfera da sociedade, esfera da economia, esfera do Direito, esfera do poder) - e cuja constituição são os poderes éticos (aspirações que movem as ações humanas). Assim, é nos poderes éticos que situa-se o poder educador do conhecimento histórico, em especial porque dele participa, fazendo-se presente nas relações humanas, que são éticas na medida em que educam, e educam devido ao fato de terem o ético como imperativo (DROYSEN, 2009).

Abordando o trabalho histórico segundo "seus trabalhadores", o teórico trata especificamente dos sujeitos históricos no mundo ético, dando destaque ao papel dos historiadores e da pesquisa histórica nesse mundo. Nesse sentido, em tom teleológico hegeliano, Droysen enfatiza:

Toda mudança no mundo histórico se realiza a partir de um dado estado de coisas que desenvolvem uma contraimagem ideal, isto é, a ideia de como as coisas deveriam ser, e tudo fica impregnado dessa ideia, desses caracteres que procuram preencher esse padrão. A condição do ser, assim impregnado, é da ordem da paixão, que vem sob a obrigação e responsabilidade e em ação e pensamento [...]. Os pensamentos são a crítica daquilo que é e que não é como deveria ser. No momento em que os pensamentos concretizados se aperfeiçoam criando novas situações, e depois se condensam, tornando-se hábito, inércia, rigidez, a crítica é renovadamente desafiada, e assim por diante. A continuidade desses pensamentos - aqueles que detêm a tocha transmiti-la-ão aos outros - é a dialética da História ("Filosofia da História" de Hegel). A partir das situações se formam novas ideias e a partir das ideias se formam novas situações, isto constitui o trabalho do ser humano (DROYSEN, 2009, p. 72-73). 
As ações humanas desdobradas de poderes éticos (aspirações, ideais etc.) e simultaneamente transformadoras do mundo ético (mundo humano consciente historicamente) respeitam uma continuidade temporal que tende a mudar os sentidos e os rumos da História, sobretudo em função do surgimento de novos poderes éticos. Nesse processo histórico, a formação dos novos poderes éticos respeita uma dialética histórica em que tese (estado de coisas), antítese (crítica a esse estado de coisas) e síntese (novo estado de coisas) formulam um movimento ininterrupto no qual os historiadores e a pesquisa histórica possuem um papel fundamental, ao passo que "Pressentir, expressar, concretizar no movimento do mundo ético as novas ideias é grandeza histórica, é 'imprimir sua marca no tempo que passa”' (DROYSEN, 2009, p. 74).

Por último, tematizando o trabalho histórico segundo "seus fins", ainda sob a influência da teleologia hegeliana, Gustav Droysen parte da ideia segundo a qual todo o processo histórico de evolução e crescimento consiste em um movimento em direção a uma finalidade que, realizando-se no movimento, objetiva a autoconsciência humana. Entretanto, "O fim mais elevado, o que condiciona incondicionalmente, aquele que move a todos, abrange todos, esclarece todos, este é o fim supremo, que não pode ser descoberto empiricamente" (DROYSEN, 2009, p. 74), pois o mundo dos homens e sua História (mundo ético) são apenas partículas em uma teofania. Nesta medida, Droysen aponta: "A História é o saber da humanidade de si mesma, a certeza de si mesma. Ela não é a "luz e a verdade", mas um procurar por ela, um sermão sobre ela, uma consagração sobre ela [...]” (DROYSEN, 2009, p. 76).

Com efeito, para Droysen, o conhecimento histórico auxilia os seres humanos em sua autoconsciência. Por esse motivo ele propõe que, assim como “[...] o filósofo pensa, o artista trabalha, o juiz julga, o historiador pesquisa" (DROYSEN, 2009, p. 71), sendo a História, desse modo, a consciência da humanidade em sua caminhada para a liberdade: pulso vital do movimento histórico. O procedimento de historicizar o passado na perspectiva droyseana implica necessariamente uma perspectiva histórica do sujeito do conhecimento histórico no presente. $\mathrm{O}$ passado objetivo presentificado pelos historiadores, além de influenciar seus destinatários, também repercute neles próprios. Assim, conhecê-lo com auxílio da ciência histórica consiste em uma forma de autoconhecimento (ASSIS, 2014a).

Cabe destacar que, aproximadamente no último terço do século XVIII, ocorreu a configuração do moderno conceito de História, com o abandono da distinção entre os termos

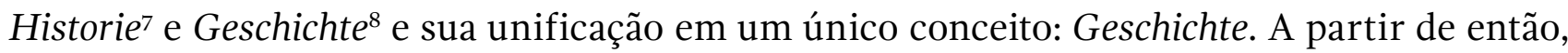
Historie (múltiplas histórias) é reconfigurado em Geschichte (única história), indicando um novo espaço de experiência e um novo horizonte de expectativas, pois Geschichte: a "história em si", como um "singular coletivo", passou a abarcar todas as histórias individuais no interior de uma história universal, abrindo caminho para maiores abstrações, bem como reunindo experiências e reflexão sobre elas em um único conceito.

Referindo-se a conhecimento, narrativa e ciência da História.

8 Adotado para significar conjunto de acontecimentos. 
Assim, uma percepção da ordem temporal pautada na noção de tempo estático, sincrônico e articulador entre passado, presente e futuro em uma continuidade, fundou as bases para uma justificação exemplar da historiografia ${ }^{9}$. Nesta medida, a predisposição que encarava os acontecimentos históricos pelo caráter coletivo e possibilidade de repetição foi suplantada por uma nova percepção temporal, na qual o tempo, considerado acelerado e sempre inédito - influência da Revolução Francesa -, passou a ser visto como um movimento único, linear e universal - tal como concebido pelas filosofias da história -, porém distinto em ordens (passado, presente e futuro) e cujos acontecimentos seriam sempre singulares, irrepetíveis - tal como concebido pelo Historicismo (KOSELLECK, 2006, p. 41-60) .

Com efeito, o resultado mais contundente desse processo de historicização do passado, presente e futuro consistiu na inviabilidade da exemplaridade do pretérito para o presente e o futuro, pois “[...] se modificou o potencial prognosticador das velhas Historien. Sua tarefa tradicional de servir de mestra para a vida deixou de existir tão logo não foi possível comprovar situações análogas das quais se pudesse tirar conclusões para o próprio comportamento (KOSELLECK, 2013, p. 160-161). Destarte, a concepção de História como Geschichte, temporalmente propôs um espaço de experiências (presente e passado articulados) totalmente novo e no qual o horizonte de expectativas (futuro) não pôde mais ser alicerçado na experiência pretérita, sobretudo por sua singularidade. Em poucas palavras, a justificação exemplar da historiografia foi suprimida pelo próprio conceito moderno de História e sua concepção temporal. Nesta ambiência, Gustav Droysen foi um dos primeiros intelectuais a extrair da crítica à "justificação exemplar da historiografia” um realinhamento. Arthur Alfaix Assis faz uma reflexão precisa sobre isso, que merece ser exposta, apesar de longa. Ele afirma:

Para ele, produtores e receptores do conhecimento histórico deviam concentrar-se não na transmissão e no aprendizado de máximas concretas de conduta prática, mas, sim, no desenvolvimento de certas habilidades de pensamento. "Pensamento histórico" torna-se, assim, a etiqueta de uma significativa mudança de paradigma. [...] Quando falava em "pensamento histórico”, Droysen dava destaque à sua percepção de que história se faz sempre na conexão entre passado e presente (e futuro, naturalmente). [...] A capacidade de pensar historicamente confunde-se, assim, com a habilidade para historicizar o passado e o presente. Para Droysen, a historicização do passado implica necessariamente uma perspectivação histórica do sujeito do pensamento histórico no presente. Droysen exprime aqui o núcleo duro da teoria historicista do conhecimento, nos quadros da qual o passado objetivo tornado conhecido pelos historiadores repercute dentro do próprio sujeito do conhecimento e dos seus destinatários. [...] Uma importante costura dessa teoria historicista do conhecimento é executada pelo conceito idealista e neo-humanista de Bildung. "Que se aprenda a

9 Tal justificação exemplar da historiografia partia da ideia de História como magistra vitae, frase cunhada pelo retórico romano Cícero, caracterizando a História como uma coleção de exemplos que serviam à conduta moral dos homens. Nesta medida, havia uma perspectiva que contava com a "futuridade do passado": a expectativa de que o futuro se assemelharia ao passado. Assim, os acontecimentos pretéritos registrados e resguardos pela historiografia eram tidos como guias para os homens no presente e no futuro. Cf. KOSELLECK, 2006. 
pensar historicamente" é uma fórmula associada a uma pretensão formativa - no sentido alemão do termo "formação". [...] Para Droysen, o pensamento histórico é um dos meios da Bildung, da autoformação resultante da internalização subjetiva do estoque cultural acumulado no decurso da história da humanidade. [...] Segundo ele, embora o conhecimento histórico seja um óbvio produto do pensamento histórico, este último, inversa e dialeticamente, também representa a meta final do conhecimento. Isso implica que os historiadores tenham por tarefa não só o pensar historicamente, mas também transmitir socialmente a maneira de pensar que é característica do seu método geral de trabalho. A transmissão e a difusão do pensamento histórico tornam-se, deste modo, a grande função educadora da historiografia (ASSIS, 2014a, p. 10-12).

Gustav Droysen chega ao final de sua Historik (Teoria da História) com a Tópica (Topik), que consiste nas formas de exposição daquilo que foi historicamente pesquisado, isto é, o estágio da "operação historiográfica" no qual o historiador oferece a "[...] prestação de contas de seu propósito e de seus resultados" (DROYSEN, 2009, p. 77). Demonstrando ciência da natureza dupla dos objetos da pesquisa histórica - elementos ainda disponíveis no presente e ideias sobre ocorrências e estado de coisas no passado -, Droysen deixa claro que, não obstante seu êxito, as ideias expostas como resultados não cobrirão a abundância de conteúdo, movimento, variedade de configurações e energia real que as ações tomadas como passado possuíam em seu presente, em especial porque, independentemente da forma de exposição, a compreensão será apenas parcial e inerente aos pontos de vista do presente (e do historiador) atinentes ao estado de coisas do tempo pretérito. Por isso mesmo, "A exposição de resultados da pesquisa será mais correta na medida em que se conscientiza tanto do que não sabe quanto do que já sabe” (DROYSEN, 2009, p. 79). Tais formas de exposição, nestes termos, consistem na exposição interrogativa, exposição narrativa, exposição didática e exposição discursiva.

No tocante à exposição interrogativa, Droysen destaca que ela requer a forma da pesquisa no fito de apresentar os resultados. Assim, “[...] ela procede como se o que finalmente foi encontrado na investigação deve ser ainda encontrado ou melhor pesquisado. Ela é uma mímese do ato de procurar [...]” (DROYSEN, 2009, p. 79). Na verdade, esse modelo de exposição consiste em deixar evidente aos receptores dos textos históricos que os resultados apresentados são parciais, não apontando um fim definitivo, mas, sim, ressaltando a possibilidade de continuidade de investigação acerca do objeto e/ou época pesquisada.

Acerca da exposição narrativa, o teórico enfatiza seu caráter de mímese da sequência de fatos, porém, “[...] somente de modo aparente os fatos falam por si, sozinhos, exclusivamente, objetivamente. Eles seriam mudos sem o narrador que os deixa falar. Não é a "objetividade que é a melhor glória do historiador. Sua maior justiça é buscar compreender" (DROYSEN, 2009, p. 80). Esse quadro genérico dos acontecimentos traçado pela exposição narrativa e criticado por Droysen consiste em uma refuta direta à postura de Leopold von Ranke e sua máxima - objeto de muitos equívocos interpretativos - segundo a qual os historiadores deveriam narrar os fatos "tal como eles ocorreram". Nesta medida, o teórico mais uma vez 
dá mostras que não poderia ser enquadrado no hall dos historiadores do século XIX que pretendiam resguardar a objetividade do conhecimento histórico por um "culto" do fato histórico por meio da "narrativa factual" (BARROS, 2011).

No que tange à exposição didática, Gustav Droysen destaca sua importância instrutiva para o presente; residente na noção de continuidade, não como modelo para imitação ou regra para o uso, mas devido ao fato de ser vivida e revivida em espírito, isto é, sendo um repertório de ideias que fornece matéria a ser julgada e colocada à prova para purificar. Desta maneira, a forma mais adequada da exposição didática consiste no ensino histórico da juventude, sobretudo se for transmitido por um professor que prime pelo movimento mais livre possível das ideias históricas instrutivas, bem como realize pesquisas autônomas, “[...] dando testemunho do espírito mediante constantes renovações [...]" (DROYSEN, 2009, p. 82).

Por fim, o teórico chega à exposição discursiva ressaltando que tal modelo procura organizar os resultados da pesquisa histórica sob um ponto de vista determinado, no fito de lançar alternativas ao esclarecimento de questões de seu tempo presente. Com isso,

Os pontos a serem validados na discussão situam-se em parte no sujeito do qual se trata - portanto, essa nação, esse poder, essa igreja, etc., foram definidos dessa ou daquela forma por seus antecedentes históricos (p.ex. sint ut sun aut non sint [foram como eles são ou não foram]) -, em parte nas coisas que se aproximam condicionando e determinando, e também em como devem ser encontrados, esclarecidos e aproveitados os momentos que continuam determinando cada fato momentâneo de acordo com sua correlação histórica (DROYSEN, 2009, p. 83).

\section{Considerações finais}

Em face da Teoria da História (Historik) de Gustav Droysen, uma questão emerge como crucial: no momento atual de modernidade reflexiva, que muitos tendem em classificar com "pós-moderno"10, qual é a sua importância para os estudos históricos? A resposta não é simples, porém pode ser esboçada à luz de algumas considerações importantes, cuja essência leva em conta a própria historicidade do conhecimento histórico.

Como é sabido, na conjuntura da virada dos anos de 1960 para 1970, o conhecimento histórico passou por uma guinada expressiva. Por um lado, o pós-estruturalismo, especialmente vinculado à Michel Foucault (2008), propôs, entre outras coisas, a modificação da noção de documento histórico, a ênfase nas descontinuidades históricas e a necessidade de matizar os discursos. Por outro, o narrativismo historiográfico, na corrente aberta pela "virada linguística", adotando métodos da crítica literária - remodelada pela psicanálise, linguística e semiótica -, sobretudo à luz de Hayden White, sugeriu problematizações críticas acerca das categorias

10 Exemplos de estudos nessa perspectiva são os publicados por Jean-François Lyotard e Keith Jenkins, que acentuam estarmos em um estágio "pós-moderno" da História, sugerindo automaticamente a ideia de uma ruptura com a modernidade, na medida em que ocorre um declínio das metanarrativas criadas no interior dela. Cf. LYOTARD, 2000; JENKINS, 2001. Não compactuamos com tal análise, pois, assim como Anthony Giddens (1991), acreditamos que vivemos em um período histórico de "modernidade reflexiva", no qual os parâme- 
e modelos de escrita da História com base em análises de seus protocolos linguísticos. Na esteira dessas reflexões, convencidos dessa modificação da noção de documento histórico, da necessidade de abandono de uma História global, da necessidade de matização dos discursos, bem como dos modos de narrativização da História, os historiadores se viram instados, por um lado, em uma reflexão mais sistemática acerca da epistemologia de seu conhecimento e, por outro, em uma profunda descrença nas propostas de uma História teleológica presente nas grandes narrativas modernas - de cunho iluminista, idealista e marxista ${ }^{11}$.

Com efeito, é a partir desse estado de espírito que os historiadores se desinteressam por uma História total e/ou global da continuidade, construída por meio de séries cronologicamente organizadas em vista de uma razão teleológica e passam a atribuir maior privilégio às descontinuidades históricas, com base nas quais se torna possível discutir fragmentos de História, inúmeras probabilidades interpretativas acerca de dado momento histórico, enfim, uma pluralidade de Histórias. Esse empreendimento, que o historiador francês François Dosse classificou de "História em migalhas" (DOSSE, 1992), conduz as reflexões epistemológicas da historiografia a inúmeras consequências, sendo uma das principais a investigação sistemática da validade científica ou não do conhecimento histórico por meio da problematização de seus processos de produção ${ }^{12}$.

É justamente no interior desse debate que a Teoria da História (Historick) de Johann Gustav Droysen se inscreve com muita vivacidade. Atribuindo ênfase na tese segundo a qual a compreensão deve ser tomada como método histórico, Droysen mantém-se em um plano médio de articulação de duas características básicas do historicismo alemão: estabelecimento de um método próprio para a ciência da História e remissão à interioridade do indivíduo (SCHULZ, 1977 apud CALDAS, 2007). Nesta medida, se no início do século XIX, sobretudo a partir de Leopold von Ranke, o conhecimento histórico distanciou-se da metafísica, na metade daquele século, com Droysen, ele encontrou uma metodologia específica de validade científica, sem, no entanto, abdicar da dimensão filosófica (ética) e da liberdade e do papel do sujeito (historiador) diante de seu objeto (História), tampouco desconsiderar a força e importância das ciências naturais. Dessa forma, Droysen demonstrou-se um intelectual antenado com o desenvolvimento reflexivo acerca do lugar da História no campo das ciências e, simultaneamente, das discussões em torno da própria historicidade do sujeito do conhecimento histórico, tão em voga nos estudos históricos contemporâneos.

\footnotetext{
tros imanentes da própria modernidade influenciam diretamente uma autocrítica, sem ultrapassagem desses mesmos parâmetros no universal social, mas, sim, de reflexão sistemática e inúmeros deslocamentos. Cf. GIDDENS, 1991; GIDDENS et al., 1997.

${ }_{11}$ Em suma, como expressa Anthony Giddens, "[...] descobrimos que nada pode ser conhecido com alguma certeza, desde que todos os "fundamentos" preexistentes da epistemologia se revelaram sem credibilidade; que a "História" é destituída de teleologia e consequentemente nenhuma versão de "progresso" pode ser plausivelmente defendida; e que uma nova agenda social e política surgiu com a crescente proeminência de preocupações ecológicas e talvez de novos movimentos sociais em geral; [...] a radicalização da modernidade é tão perturbadora, e tão significativa. Seus traços mais conspícuos - a dissolução do evolucionismo, o desaparecimento da teleologia histórica, o reconhecimento da reflexividade meticulosa, constitutiva, junto com a evaporação da posição privilegiada do Ocidente — nos levam a um novo e inquietante universo de experiência" (GIDDENS, 1991, p. 45-51).

${ }_{12}$ Em uma bibliografia extensa, gostaríamos de destacar respectivamente, Cf. ANKERSMITH, 2012; BARTHES, 2004; CERTEAU, 2007; GINZBURG, 2002, 2007; RICOEUR, 1994; RÜSEN, 2010abc; VEYNE, 2008; WHITE, 2008.
} 
Sua Teoria da História (Historik), neste sentido, lançou as bases hermenêuticas para se pensar as ciências do espírito, tal como desenvolvida por Wilhelm Dilthey (2010) e HansGeorg Gadamer (1999), como também anteviu a crise do historicismo no início do século XX (WHITE, 2008). Além disso, Droysen procurou mapear a maneira pela qual o conhecimento histórico consegue atribuir sentido ao mundo humano, que se torna histórico somente a partir da consciência da historicidade. Por esse motivo, sua Teoria da História (Historik) é recuperada por Jörn Rüsen (2010abc), no fito de vincular o conhecimento histórico à vida prática dos indivíduos, sem perder sua essência científica, na medida em que ele surge nas carências de orientação dos homens e seu resultado possui funções de orientação existencial, fundamental à própria existência com sentido no fluxo histórico.

Em última instância, cabe ressaltar que, a partir da Teoria da História (Historik), de Johann Gustav Droysen, podemos nos mover no interior da modernidade reflexiva, pois, em um contexto de certezas e inquietudes (CHARTIER, 2002) epistemológicas atinentes à validade do conhecimento histórico e sua verdadeira tarefa, sobretudo em que os parâmetros imanentes da própria modernidade influenciam diretamente uma autocrítica, o seguinte argumento de Droysen se revela muito atual:

Nossa ciência não pretende que seu método de pesquisa seja o único a reger sua atividade científica. E ela tem a humildade de reconhecer que, sem suas exposições de resultados, não tem condições de oferecer mais do que faz parte de seu domínio de pesquisa, nem além do que seus métodos possibilitam. E no momento em que ela tem consciência de não poder mais responder, ou não oferecer resposta satisfatória a muitas perguntas de seu campo, então ela redobrará seus cuidados, a fim do que o que ela forneça não pareça ter mais valor do que realmente tem ou pode ter, a saber: uma representação mais próxima do passado de coisas distantes ou muito remotas que foram um presente, que agora são parte integrante de nossa realidade e ainda vivem e convivem no conhecimento dos homens (DROYSEN, 2009, p. 85).

\section{Referências}

ANKERSMITH, Frank Rudolf. A Escrita da História: a natureza da representação histórica. Londrina: Editora da UEL, 2012.

ASSIS, Arthur Alfaix. Johann Gustav Droysen (1808-1884). In: MARTINS, Estevão de Rezende (org.). A História pensada: teoria e método na historiografia europeia do século XIX. São Paulo: Contexto, 2010. p. 31-36.

ASSIS, Arthur Alfaix. A didática da História de J. G. Droysen: constituição e atualidade. Revista Tempo, Niterói, v. 20, p. 1-18, 2014a. https://doi.org/10.20509/TEM-1980-542X2014V203609 ASSIS, Arthur Alfaix. What is history for? Johann Gustav Droysen and the functions of historiography. Oxford: Berghahn Books, 2014b.

BARTHES, Roland. O rumor da língua. Trad. Mário Laranjeira. São Paulo: Martins Fontes, 2004. 
BARROS, José D’Assunção. Droysen: os desdobramentos relativistas do historicismo. In: BARROS, José D'Assunção. Teoria da História: acordes historiográficos - uma nova proposta para a teoria da História. 2. ed. Petrópolis, RJ: Vozes, 2011. p. 97-128.

BENTIVOGLIO, Julio. Apresentação. In: DROYSEN, Johann Gustav. Manual de Teoria da História. Trad. Sara Baldus e Julio Bentivoglio. Petrópolis, RJ: Vozes, 2009, p. 1-26.

BENTIVOGLIO, Julio. Cultura política e historiografia Alemã no século XIX: A escola historische Zeitschrift. Revista de Teoria de História, Goiânia, v. 1, p. 20- 58, 2010.

BLOCH, Marc. Apologia da História, ou o oficio do historiador. Rio de Janeiro: Jorge Zahar Editor, 2001.

CALDAS, Pedro S. P. Que significa pensar historicamente: uma interpretação da teoria da história de Johann Gustav Droysen. 2004. Tese (Doutorado em História) - Pontifícia Universidade Católica do Rio de Janeiro, Rio de Janeiro, 2004.

CALDAS, Pedro S. P. A atualidade de Johann Gustav Droysen: uma pequena História de seu esquecimento e se suas interpretações. Lócus, Juiz de Fora, v.12, n. 1, p. 95-111, 2006.

CALDAS, Pedro S. P. As dimensões do historicismo: um estudo dos casos alemães. Opsis, Catalão, v. 7, n. 9, p. 47-66, jul.-dez. 2007.

CALDAS, Pedro S. P. Os Fundamentos clássicos da concepção de História de Johann Gustav Droysen: Esboço de uma investigação. Liber Intellectus, Jaguariúna, v. 1, p. 1-18, 2007.

CALDAS, Pedro S. P. Uma dificuldade no caminho do historicismo: uma leitura de Droysen com filtro marxista. In: ARAUJO, V. L.; MATA, S. R.; MOLLO, H. M.; VARELLA, F. F. (org.). A dinâmica do historicismo: revisitando a historiografia moderna. Belo Horizonte: Argumentum, 2008. p. 107-124.

CALDAS, Pedro S. P. Hans-Georg Gadamer e a Teoria da História. Dimensões, Vitória, v. 24, p. 55-74, 2010.

CALDAS, Pedro S. P. Johann Gustav Droysen (1808-1884). In: PARADA, Maurício (org.). Os historiadores clássicos da História: de Tocqueville a Thompson. Rio de Janeiro: PUC-Rio; Petrópolis: Vozes, 2013. p. 36-55.

CERTEAU, Michel de. A escrita da História. Rio de Janeiro: Forense-Universitária, 2007.

CHARTIER, Roger. À beira da falésia: a História entre incertezas e inquietude. Tradução de Patrícia Chittoni Ramos. Porto Alegre: Ed. Universidade/UFRGS, 2002.

CROCE, Benedetto. História, pensamento e ação. Tradução de Darcy Damasceno. Rio de Janeiro: Zahar, 1964.

DILTHEY, Wilhelm. A construção do mundo histórico nas Ciências Humanas. São Paulo: UNESP, 2010.

DOSSE, François. A História em Migalhas. São Paulo: Ensaio, Campinas, SP: Editora Universidade Estadual de Campinas, 1992.

DROYSEN, Johann Gustav. Historik - Rekonstruktion der ersten vollständigen Fassung der Vorlesungen (1857). Peter Leyh (rrg). Stuttgart, Bad-Canstatt: Fromann-Holzboog, 1977. DROYSEN, Johann Gustav. Manual de Teoria da História. Petrópolis, RJ: Vozes, 2009.

FOUCAULT, Michel. A arqueologia do saber. 7. ed. Rio de Janeiro: Forense Universitária, 2008. 
GADAMER, Hans-Georg. Verdade e método. 3. ed. Tradução: Flávio Paulo Meurer. Petrópolis, RJ: Vozes, 1999. 2 v.

GUERRA, Francesco. Riflessioni sul prussianesimo di Johann Gustav Droysen. Ricerche di Storia Politica, Bologna, v. 16, p. 59-70, 2013

GERVINUS, Georg. Fundamentos de teoria de História. Petrópolis, RJ: Vozes, 2010.

GIDDENS, Anthony. As consequências da modernidade. Tradução de Raul Fiker. São Paulo: Editora da Unesp, 1991.

GIDDENS, Anthony. et. al. Modernização reflexiva: política, tradição e estética na ordem social Moderna. Tradução de Magda Lopes. São Paulo: Editora da Unesp,1997.

GINZBURG, Carlo. Relações de Força. História, retórica, prova. São Paulo: Companhia das Letras, 2002.

GINZBURG, Carlo. O fio e os rastros. Verdadeiro, falso, fictício. Trad. Eduardo Brandão e Rose Freire d'Aguiar. São Paulo: Companhia das Letras, 2007.

JENKIS, Keith. A istória repensada. São Paulo: Contexto, 2001.

KOSELLECK, Reinhart. Futuro Passado: contribuição à semântica dos tempos históricos. Rio de Janeiro: Contraponto; Editora PUC Rio, 2006.

KOSELLECK, Reinhart. O conceito de História. Belo Horizonte: Autêntica, 2013.

LYOTARD, Jean-François. A condição pós-moderna. 6. ed. Rio de Janeiro: José Olympio, 2000.

MARTINS, Estevão de Rezende. Historicismo: tese, legado, fragilidade. História Revista, Goiânia, v. 7, n. 1/2, jan./dez. 2002, p. 1-22. https://doi.org/10.5216/hr.v7i1.10480

MARTINS, Estevão de Rezende. Historicismo: o útil e o desagradável. In: ARAUJO, Valdei Lopes de; MOLLO, Helena Miranda; VARELLA, Flávia Florentino; MATA, Sérgio Ricardo da (org.). A dinâmica do historicismo: revisitando a historiografia moderna. Belo Horizonte, MG: Agvmentvm, 2008.

MARTINS, Estevão de Rezende. Introdução: o renascimento da História como ciência. In: MARTINS, Estevão de Rezende. (org.). A História pensada: teoria e método na historiografia europeia do século XIX. São Paulo: Contexto, 2010. p. 7-14.

RICOEUR, Paul. Tempo e narrativa. Trad. Constança Marcondes Cesar. Campinas, SP: Papirus, 1994, 3 t.

RÜSEN, Jörn. Begriffene Geschichte: Genesis und Begründugn der Geschichtstheorie J. G. Droysens. Paderborn: Schöningh, 1969.

RÜSEN, Jörn. Razão histórica: teoria da História I: os fundamentos da ciência histórica. Trad. Estevão de Rezende Martins. Brasília: Ed. da UNB, $2010 a$.

RÜSEN, Jörn. Reconstrução do passado: teoria da História II: os princípios da pesquisa histórica. Trad. Asta-Rose Alcaide e Estevão de Rezende Martins. Brasília: Ed. da UNB, 2010b.

RÜSEN, Jörn. História viva: teoria da História III: formas e funções do conhecimento histórico. Trad. Estevão de Rezende Martins. Brasília: Ed. da UNB, 2010c.

SAMMER, Renata. A ética historista de J. G. Droysen. 2012. Dissertação (Mestrado em História) - Pontifícia Universidade Católica do Rio de Janeiro, Rio de Janeiro, 2012. 
SIMIAND, François. Método histórico e ciência social. Tradução de José Leonardo do Nascimento. Bauru/SP: Edusc, 2003.

SILVA, Luiz Sérgio Duarte da. Droysen: A fundamentação da ciência da História pela via de produção de uma antropologia histórica. História Revista, Goiânia, v. 7, n. 1/2, p. 151- 156, jan./dez. 2002.

VEYNE, PAUL. Como se escreve a História: Foucault revoluciona a História. 4. ed. Brasília: Editora da UnB, 2008.

WHITE, Hayden. Meta-História: a imaginação histórica do século XIX. 2. ed. São Paulo: EDUSP, 2008.

Recebido em: 14/9/2017.

Aprovado em: 7/5/2019.

\section{Julierme Morais}

Universidade Estadual de Goiás (UEG)

E-MAIL: juliermemorais27@gmail.com

ORCID: http://orcid.org/0000-0001-5257-6691

Instituição: Universidade Estadual de Goiás (UEG), Campus Morrinhos. Endereço postal: R. Quatorze, 327 - Jd. América, Morrinhos - GO. CEP: 75650000 